\title{
Management of isolated zygomaticomaxillary complex fractures with an individualized approach: a retrospective study
}

\author{
Rahul Datta ${ }^{1}$, Kanwar Harit', Yasmin Grewal' \\ ${ }^{1}$ Department of Oral and Maxillofacial Surgery, Rayat Bahra Dental College and Hospital, Mohali 140104, Punjab, India. \\ ${ }^{2}$ Department of Public Health Dentistry, Rayat Bahra Dental College and Hospital, Mohali 140104, Punjab, India.
}

Address for correspondence: Dr. Rahul Datta, H. No. 416, Sector 37 A, Chandigarh 160036, India. E-mail: docdatta@gmail.com

\begin{abstract}
Aim: Fractures of the zygomatico maxillary complex (ZMC) are commonly seen after traumatic injuries to the facial skeleton. The aim of the study was to review the outcome of individualized treatment approach in the management of isolated ZMC fractures. Methods: A retrospective analysis of 25 patients was conducted to assess the outcomes of isolated ZMC (iZMC) fracture treatment at a multi specialty hospital (Punjab, India) over a 3-year period. Results: Out of the 25 patients reviewed, 4 patients required no surgical intervention and 21 patients underwent surgical reduction via the buccal sulcus approach. An individualized treatment plan was formulated for each patient to decide mini plate fixation at one- two- or three-point with or without orbital rim exploration. Two patients required removal of mini plates from the buttress area on postoperative follow up. Conclusion: Our review shows that an individualized treatment approach produces the most favorable results in the management of iZMC fractures.
\end{abstract}

Key words:

Fixation, fractures, reduction, zygomatic complex

\section{INTRODUCTION}

The zygoma is a prominent bone in the facial skeleton and contributes to structural and functional stability of the craniofacial complex. Due to its location, the zygoma and its associated processes are easily fractured in a trauma. ${ }^{[1]}$ As the zygoma is usually associated with adjacent bones, fractures to this region are termed as zygomatico-maxillary complex (ZMC) fractures. Fractures of the ZMC may occur alone known as isolated ZMC (iZMC) fracture or in association with fractures of other bones of the craniofacial complex. ${ }^{[2]}$

Since the first description of surgical management of a ZMC fracture, many authors have proposed a variety of surgical approaches for reduction of the bone. In

\begin{tabular}{|l|l|}
\hline \multicolumn{2}{|c|}{ Access this article online } \\
\hline Quick Response Code: & Website: \\
\hline & www.parjournal.net \\
\hline & \\
\hline
\end{tabular}

addition, after the evolution of bone plating systems, a large number of recommendations have been made for stabilization or fixation of these fracture segments. ${ }^{[2]}$ This study presents a retrospective review of iZMC fractures, managed with an individualized approach.

\section{METHODS}

A retrospective analysis of available records over a 3-year period (from January 2011 to January 2014) was conducted to assess the treatment outcomes of iZMC fractures at a multi-specialty hospital in Punjab, India. Data relevant to the demographic profile of the patients such as age and gender, cause of injury, other associated injuries (noncranio-facial), and surgical treatment provided was collected. Only those patients with iZMC fractures without any other facial bone injury were included in this study. Patients who presented with displaced iZMC fractures causing aesthetic or functional problems that needed surgical intervention underwent standard preoperative investigations. All patients were given peri-operative antimicrobial prophylaxis, adjunct analgesics and supportive medication with restricted soft diet for 2 weeks post-treatment. Patients not requiring surgical 
intervention were also given antimicrobial prophylaxis, analgesics and were restricted to a soft diet for a 3-week period. Follow-up period for all patients ranged from 1 month to 3 months. Based on the clinical presentation and treatment modality, the fractures were classified into non-displaced or minimally displaced (low-energy), displaced fractures requiring reduction and fixation (middleenergy), and comminuted fractures involving the buttresses requiring orbital reconstruction (high-energy). ${ }^{[3]}$

Treatment outcomes were considered successful if there was no obvious facial deformity or asymmetry, no functional limitation and minimal surgical morbidity, such as scar at the site of the incision where made extra-orally. Any alteration in these outcome variables was recorded as either suboptimal treatment outcome or a complication of the procedure.

\section{RESULTS}

A total of 25 patients with iZMC fractures were included in the study. The age ranged from 17 years to 56 years, and the sample consisted of 8 females and 17 males. The reporting time after injury varied from 0 day to 6 days and the time to surgical intervention after injury ranged from 1 day to 7 days. Four patients did not require any surgical intervention. Among the patients that required surgical intervention, the following protocols were observed: (1) Reduction of the iZMC fracture segment was performed via buccal sulcus incision $(n=21)$, (2) reduction of iZMC fracture without bone plate fixation $(n=5)$, (3) one-point fixation with a bone plate at the zygomatico-maxillary (ZM) buttress $(n=4)$, (4) two-point fixation with bone plates at the ZM buttress and fronto-zygomatic (FZ) buttress $(n=6)$, (5) two-point fixation at ZM buttress and infra-orbital margin (IOM) $(n=2)$ and (6) three-point fixation at ZM buttress, FZ buttress and IOM $(n=4)$ [Table 1]. The most common cause of injury was road traffic accidents $(n=13)$. Overall, 17 surgeries were performed under general anesthesia and the remaining under local anesthesia $(n=4)$. Ten patients were classified as middle-energy group while the remaining were classified into the high-energy $(n=6)$ and low-energy $(n=6)$ groups. Surgical access to the FZ buttress and the infra-orbital rim was obtained by standardized lateral eyebrow incision and infra-orbital incision.

The treatment outcome was considered satisfactory in 19 patients that underwent surgical intervention and all patients that did not require surgery. Two patients had complications that required removal of the bone plate from the ZM buttress region. Wound dehiscence was observed on post-operative week 2 in one patient and on post-operative week 3 in another patient. These patients were treated with oral irrigation for local wound care for a total of 5 weeks post-operatively before removal of bone plates, after consolidation of bone healing. Furthermore, 2 other patients developed chronic sinusitis, which was managed by conventional antibiotic protocol, and 3 patients complained of persistent infra-orbital nerve paresthesia until the last follow-up.
Table 1: Distribution of patients by treatment protocol

\begin{tabular}{|c|c|c|c|c|c|}
\hline $\begin{array}{l}\text { Treatment } \\
\text { protocol }(n=25)\end{array}$ & Age & Gender & $\begin{array}{l}\text { Cause } \\
\text { of } \\
\text { injury }\end{array}$ & $\begin{array}{l}\text { Facial } \\
\text { side }\end{array}$ & $\begin{array}{l}\text { Type of } \\
\text { anesthesia }\end{array}$ \\
\hline \multirow{4}{*}{$\begin{array}{l}\text { No surgical } \\
\text { intervention }(n=4)\end{array}$} & 22 & Male & $\mathrm{IPV}^{*}$ & Left & - \\
\hline & 24 & Male & SPORT $^{\dagger}$ & Right & - \\
\hline & 30 & Female & $\mathrm{RTA}^{\ddagger}$ & Right & - \\
\hline & 42 & Male & RTA & Right & - \\
\hline \multirow{5}{*}{$\begin{array}{l}\text { Surgical reduction } \\
\text { only }(n=5)\end{array}$} & 28 & Female & IPV & Left & General \\
\hline & 42 & Male & FARM ${ }^{\S}$ & Right & Local \\
\hline & 20 & Female & RTA & Left & Local \\
\hline & 37 & Male & RTA & Left & Local \\
\hline & 33 & Female & RTA & Left & General \\
\hline \multirow{5}{*}{$\begin{array}{l}\text { Reduction+ZMB\| } \\
\text { fixation }(n=5)\end{array}$} & 56 & Male & RTA & Left & General \\
\hline & 27 & Male & IPV & Left & Local \\
\hline & 37 & Male & FARM & Right & General \\
\hline & 19 & Male & RTA & Right & General \\
\hline & 34 & Male & IND\# & Right & General \\
\hline \multirow{5}{*}{$\begin{array}{l}\text { Reduction+ZMB+FZB ** } \\
\text { fixation }(n=5)\end{array}$} & 31 & Female & RTA & Left & General \\
\hline & 26 & Female & RTA & Left & General \\
\hline & 17 & Male & RTA & Right & General \\
\hline & 19 & Male & IPV & Right & General \\
\hline & 19 & Female & RTA & Right & General \\
\hline \multirow{2}{*}{$\begin{array}{l}\text { Reduction+ZMB+IOM }+{ }^{+\dagger} \\
\text { fixation }(n=2)\end{array}$} & 48 & Male & IND & Left & General \\
\hline & 20 & Male & FARM & Right & General \\
\hline \multirow{4}{*}{$\begin{array}{l}\text { Reduction+ZMB+FZB+ } \\
\text { IOM fixation }(n=4)\end{array}$} & 20 & Male & RTA & Left & General \\
\hline & 32 & Male & IPV & Left & General \\
\hline & 36 & Female & IPV & Left & General \\
\hline & 32 & Male & RTA & Left & General \\
\hline
\end{tabular}

*Inter personal violence, ${ }^{\dagger}$ Sports injury, ${ }^{\ddagger}$ Road traffic accident, ${ }^{\circledR}$ Farming injury, \#Industrial accident, "Zygomatico-maxillary buttress, **Fronto-zygomatic buttress, ${ }^{\dagger}$ Infra-orbtial margin

\section{DISCUSSION}

The zygomatic complex is commonly involved in maxillofacial trauma, but iZMC fractures are less common. Fractures of the ZMC most commonly occur due to assault and motor vehicle accidents. ${ }^{[4]}$ The most common cause of iZMC was motor vehicle accidents in our sample. Bogusiak and Arkuszewski ${ }^{[5]}$ found a higher incidence of assaults in their review of ZMC fractures in the Polish population. $\mathrm{Ma}^{[6]}$ reported that $20 \%$ of patients in their study in China suffered injury due to industrial accidents while in our study only $8 \%$ of the sample suffered due to the same reason. The gender distribution of patients in this study is analogous to those reported by many studies, whereby a higher number of males suffered from iZMC fractures than females. ${ }^{[7]}$ Sometimes patients with a facial injury suffer iZMC fractures with minimal displacement of bone and no functional limitation or cosmetic derangement or deformity. Such patients need only longitudinal observation without active surgical intervention. However, displaced fractures require surgical reduction and stabilization. ${ }^{[3,4]}$ In this study, 21 out of 25 patients required surgical intervention. Majority of the patients in this study had middle-energy fractures which are similar to those reported by other authors. ${ }^{[8,9]}$

Facial edema and peri-orbital swelling may hamper clinical examination and immediate surgical procedure among these patients. Other factors that may delay surgical treatment include: preanesthetic review and investigations, 
neurological clearance in patients with possible head injury, or other traumatic injuries of the body. ${ }^{[10]}$ It is acceptable to wait for the peri-orbital edema to resolve since it allows for better palpation and manipulation of the fracture segments intraoperatively. ${ }^{[2]}$ In this study, all these reasons accounted for the delay in surgical treatment after injury ranging from 0 day to 6 days. Various surgical approaches for reduction of iZMC fractures and nonrigid methods of fixation have been proposed even with the advent of mini-plate osteosynthesis. ${ }^{[11]}$ However, recent reviews state that each case must be individualized because fixation requirements differ greatly from one fracture to another. ${ }^{[2]}$

A detailed review of iZMC fractures was performed by Ellis and Kittidumkerng. ${ }^{[8]}$ They proposed an algorithm to assess the need for fixation of reduced iZMC fractures and concluded that each case must be individualized for type of surgical fixation. As per the suggested algorithm, reduction of the fractured segment is followed by assessment of fracture line alignment and stability of the bone under controlled pressure. Further fixation is done after such evaluation. In the management of our patients with iZMC fractures, we also followed a similar protocol and primarily used exposure of the $\mathrm{ZM}$ buttress in order to reduce and assess reduction of the iZMC segment. This approach has also been successfully used for primary reduction by other authors..$^{[4,12]}$ Palpation of orbital margins was also performed to confirm the reduction. Need for surgical fixation was determined by evaluating the stability of the fracture segments when force was applied judiciously. In patients with clinical and radiographic features suggestive of orbital floor involvement, surgical exploration via infra-orbital incision was performed. In all other patients, infra-orbital reduction was visually confirmed with exploration via the maxillary sulcus incision.

It is recommended to use low profile titanium mini-plates for the management of ZMC fractures as they provide improved cosmesis and less discomfort to the patients. ${ }^{[8,9,13]}$ In this study, low-profile titanium mini-plates were used in seven patients while stainless steel plates were used in 14 patients mainly due to financial constraints of the patients. Different protocols have been proposed for the site of fixation and points of fixation of iZMC fragments. These range from no fixation to one-point fixation, ${ }^{[4]}$ two-point fixation ${ }^{[14]}$ and even three-point fixation. ${ }^{[15]}$ In this study, 7 patients underwent two-point fixation, and 4 patients underwent three-point fixation. Decision of number and points of fixation was done as per Ellis and Kittidumkerng's protocol as mentioned above. ${ }^{[8]}$ Exploration of the orbital rim and floor is also a controversial topic in management of ZMC fractures. Most authors recommend that it should be performed only if necessary. ${ }^{[3]}$ In this study, exploration and repair of the orbital floor was performed in only 6 patients when it was indicated on preoperative evaluation or during surgical exposure of the $\mathrm{ZM}$ buttress and reduction of the fracture fragments.

Many authors have noted complications in the management of iZMC fractures and they range from malunion, improper reduction, failure of hardware, aesthetic and functional impairment..$^{[4,14,16]}$ In this study, bone plates were removed in two patients due to dehiscence of the oral wounds. No other significant complications were noted. Two patients complained of persistent infra-orbital nerve paresthesia, which is an accepted side effect of ZMC fractures and their treatment. This side effect may or may not be related to actual surgical manipulation. ${ }^{[17]}$

Our review of patients with iZMC fractures shows that an individualized approach to need for surgical reduction and type of fixation provides optimum outcomes with minimal complications.

\section{ACKNOWLEDGEMENT}

We would like to thank the faculty and staff of Cheema Medical Complex, Mohali, Punjab, where the surgical work and patient care was performed.

\section{REFERENCES}

I. Chowdhury SK, Menon PS. Etiology and management of zygomatico-maxillary complex fractures in the armed forces. Med J Armed Forces India 2005;61:238-40.

2. Ellis E. Fractures of the zygomatic complex and arch. In: Fonseca RJ, Walker RV, Betts NJ, editors. Oral and Maxillofacial Trauma. 3rd ed., Vol. I. Philadelphia, PA: Saunders Elsevier; 2005. p. 583-94.

3. Bailey JS, Gold Wasser MS. Management of zygomatic complex fractures. In: Miloro M, editor. Peterson's Principles of Oral and Maxillo Facial Surgery. 2nd ed., Vol. I. Hamilton, London: BC Decker Inc.; 2004. p. 45I-3.

4. Lee EI, Mohan K, Koshy JC, Hollier LH Jr. Optimizing the surgical management of zygomaticomaxillary complex fractures. Semin Plast Surg 2010;24:389-97.

5. Bogusiak K, Arkuszewski P. Characteristics and epidemiology of zygomaticomaxillary complex fractures. J Craniofac Surg 2010;21:1018-23.

6. Ma JJ. Treatment of zygomaxillary complex multiple fractures: an analysis of 25 consecutive cases. Shanghai Kou Qiang Yi Xue 2004; 13:21 9-21. (in Chinese)

7. Tadj A, Kimble FW. Fractured zygomas. ANZJ Surg 2003;73:49-54.

8. Ellis E 3rd, Kittidumkerng W. Analysis of treatment for isolated zygomaticomaxillary complex fractures. J Oral Maxillofac Surg 1996;54:386-400.

9. Hollier LH, Thornton J, Pazmino P, Stal S. The management of orbitozygomatic fractures. Plast Reconstr Surg 2003; I I I:2386-92.

10. Kovács AF, Ghahremani M. Minimization of zygomatic complex fracture treatment. Int J Oral Maxillofac Surg 2001;30:380-3.

II. O'Sullivan ST, Panchal J, O'Donoghue JM, Beausang ES, O'Shaughnessy M, O'Connor TP. Is there still a role for traditional methods in the management of fractures of the zygomatic complex? Injury 1998;29:4I3-5.

12. de Souza Carvalho AC, Pereira CC, Queiroz TP, Magro-Filho O. Intraoral approach to zygomatic fracture: modified technique for infraorbital rim fixation. J Craniofac Surg 2012;23:537-8.

13. Prein J. Manual of Internal Fixation in the Cranio-Facial Skeleton. New York: Springer-Verlag; 1998. p. 135

14. Menon S, Sinha R, Thapliyal G, Bandyopadhyay T. Management of zygomatic complex fractures in a tertiary hospital: a retrospective study. J Maxillofac Oral Surg 201 I; 10:138-41.

15. Rana M, Warraich R, Tahir S, Iqbal A, von See C, Eckardt AM, Gellrich NC. Surgical treatment of zygomatic bone fracture using two points fixation versus three point fixation - A randomised prospective clinical trial. Trials 2012;13:36.

16. Zhang QB, Dong YJ, Li ZB, Zhao JH. Minimal incisions for treating zygomatic complex fractures. J Craniofac Surg 201 I;22:1460-2.

17. Peltomaa J, Rihkanen $\mathrm{H}$. Infraorbital nerve recovery after minimally dislocated facial fractures. Eur Arch Otorhinolaryngol 2000;257:449-52.

How to cite this article: Datta R, Harit K, Grewal Y. Management of isolated zygomaticomaxillary complex fractures with an individualized approach: a retrospective study. Plast Aesthet Res 2014;1:51-3.

Source of Support: Nil, Conflict of Interest: None declared.

Received: 23-05-2014; Accepted: 10-07-2014 